University of Nebraska - Lincoln

DigitalCommons@University of Nebraska - Lincoln

Publications from USDA-ARS / UNL Faculty

U.S. Department of Agriculture: Agricultural

Research Service, Lincoln, Nebraska

2000

Detection of parasitised fly puparia using near infrared spectroscopy

Floyd E. Dowell

USDA-ARS

Alberto B. Broce

Kansas State University

Feng Xie

Kansas State University

James E. Throne

USDA-ARS, Manhattan, KS, james.throne@ars.usda.gov

James E. Baker

USDA-ARS

Follow this and additional works at: https://digitalcommons.unl.edu/usdaarsfacpub

Dowell, Floyd E.; Broce, Alberto B.; Xie, Feng; Throne, James E.; and Baker, James E., "Detection of parasitised fly puparia using near infrared spectroscopy" (2000). Publications from USDA-ARS / UNL Faculty. 2039.

https://digitalcommons.unl.edu/usdaarsfacpub/2039

This Article is brought to you for free and open access by the U.S. Department of Agriculture: Agricultural Research Service, Lincoln, Nebraska at DigitalCommons@University of Nebraska - Lincoln. It has been accepted for inclusion in Publications from USDA-ARS / UNL Faculty by an authorized administrator of DigitalCommons@University of Nebraska - Lincoln. 


\title{
Detection of parasitised fly puparia using near infrared spectroscopy
}

\author{
Floyd E. Dowell, ${ }^{\mathrm{a}}$ Alberto B. Broce, ${ }^{\mathrm{b}}$ Feng Xie, ${ }^{\mathrm{c}}$ James E. Throne ${ }^{\mathrm{a}}$ and \\ James E. Baker ${ }^{a}$ \\ ${ }^{a}$ USDA-ARS, Grain Marketing and Production Research Center, 1515 College Avenue, Manhattan, KS 66502, USA \\ ${ }^{b}$ Department of Entomology, 123 Waters, Kansas State University, Manhattan, KS 66506, USA \\ ${ }^{c}$ Department of Grain Science and Industry, 201 Shellenberger, Kansas State University, Manhattan, KS 66506, USA
}

\begin{abstract}
Near infrared (NIR) spectroscopy was used to identify house fly (Musca domestica $\mathrm{L}$.) puparia that contained viable parasitoids. Results derived from a partial least squares analysis of NIR spectra showed that about 80-90\% of puparia containing parasitoids could be identified correctly. Difference spectra and beta coefficients indicated that absorption differences between parasitised and unparasitised puparia may have been due to moisture content and/or differences in composition of chitin or lipid components. Detection of viable hymenopterous parasitoids within puparia could assist commercial insectaries in delivering known quantities of parasitised puparia for biological control of house flies and other filth flies and in rapidly determining levels of parasitisation of these flies in confined livestock and poultry operations.
\end{abstract}

Keywords: NIR, near infrared, spectroscopy, partial least squares regression, insects, flies, parasitoids, biological control, puparia

\section{Introduction}

House flies, Musca domestica L., and stable flies, Stomoxys calcitrans (L.) (Diptera: Muscidae), are common pests around feedlots, dairies, poultry houses and residential areas. Although adult house flies do not bite, they can be a nuisance and can also vector several disease pathogens. ${ }^{1}$ Stable flies are blood-sucking flies that can annoy livestock and cause a reduction in weight gain and performance. Fly populations can become quite large in confined livestock operations, and some urban areas have imposed tolerance thresholds for nearby agricultural facilities. ${ }^{2}$ These flies are difficult to control and reproduce rapidly by laying eggs in animal faeces and other decaying organic materials. House fly control has been confounded by development of insecticide resistance ${ }^{3}$ and elimination of some pesticides in response to public concern about the use of and exposure to chemical pesticides.

Biological control with parasitoids has been an effective means of reducing filth fly populations. Parasitic wasps in the genera Spalangia and Muscidifurax are natural enemies of house flies and other filth flies. ${ }^{2-6}$ The female parasitoid seeks out and locates a house fly puparium. This puparium, which encloses the pupa, is a barrel-shaped, sclerotised and often dark-coloured structure about $5 \mathrm{~mm}$ long formed during a process called pupariation. ${ }^{7}$ The wasp perforates the puparial cuticle with its tubular-shaped ovipositor and stings the pupa. The fe- 
male wasp generally, but not always, lays an egg, via the ovipositor, in the space between the fly pupa and the puparium wall. If the pupa has not separated from the puparium, which occurs 1-2 days after pupariation, the wasp does not lay an egg. Thus, when a group of puparia is exposed to these wasps, some will not be attacked (i.e. pupae will emerge as adult flies about one week after pupariation); some will be stung and parasitised (i.e. eggs will be laid and parasitoids will emerge 1-2 weeks later); and some will be stung but not parasitised (i.e. neither fly nor parasitoid will emerge).

When rearing parasitoids for biological control of flies, commercial insectaries do not ship parasitoids to their customers until all flies have emerged from non-attacked puparia. However, many of the remaining puparia may contain stung but unparasitised hosts or, for a variety of other reasons, may not contain viable parasitoids. After flies emerge, the percentage of remaining puparia from which no wasp will emerge can range from 20 to $100 \% .^{4,7,8}$ Some biological control failures have been attributed to a lack of information on percentage of parasitoid emergence. To maintain quality assurance and to optimise the effective use of an augmentative or inundative release strategy, commercial insectaries need a rapid means of determining parasitisation levels.

We examined the potential for using near infrared (NIR) spectroscopy to differentiate between parasitised and unparasitised fly puparia. This technology has been used in a number of agricultural applications ${ }^{9}$ including detecting parasitised and unparasitised insects inside single grain kernels ${ }^{10-12}$ and differentiating among adult insect species. ${ }^{13}$ However, NIR spectroscopy has never been used to detect parasitised fly puparia.

\section{Methods}

Insects

We obtained three groups of house fly puparia (groups 1-3) from cultures maintained in the Department of Entomology, Kansas State University, and two groups of puparia from different commercial insectaries (groups 4-5). All puparia obtained from Kansas State University were exposed to
Muscidifurax zaraptor and were reared in similar environments and on similar diets, but at different times. The two groups obtained from commercial insectaries were exposed to either Spalangia cameroni (group 4) or Muscidifurax raptorellus (group 5) (Table 1). Puparia were obtained after flies had emerged from puparia that were not attacked. Therefore, puparia selected for tests contained parasitoids with dead fly pupae, only dead fly pupae or dead fly pupae with dead parasitoids. All puparia, except those in group 1, were dissected after emergence of wasps and NIR scanning to determine if they contained a dead fly pupa or dead parasitoid.

\section{NIR spectra collection}

A diode-array NIR spectrometer (Perten Instruments, Springfield, IL) was used to collect spectra (700-1700 nm) from a single fly puparium placed manually in a vee-shaped black trough that was illuminated by a fibre-optic bundle placed above the puparium at a $45^{\circ}$ angle. The trough sides were $45^{\circ}$ from vertical. A second fibre bundle placed directly above the puparium carried reflected light to the spectrometer. The black trough was used as a reference for absorption calculations. Although white ceramic-type materials are typically used for reference readings, the fixed test apparatus could not accommodate that material. In addition, the sensor gain settings used for the highly absorbent puparia resulted in sensor saturation when highly reflective reference material was used. These problems were resolved by using the black trough both as a reference and sample holding fixture. The trough was made of black plastic material that had uniform absorption throughout the $700-1700 \mathrm{~nm}$ region and had negligible specular reflection. Since the reference standard was more absorbent than the samples, results will be presented as "relative absorbance" since most absorbance values calculated from the samples are negative. Fifteen spectra from each puparium were collected, averaged and stored by the system in about $1 \mathrm{~s}$. After spectra were collected, each puparium was placed in a container and stored in a chamber at about $27^{\circ} \mathrm{C}$ and $60 \% \mathrm{RH}$ and with a 12 : $12 \mathrm{~h}$ photoperiod. Puparia were scanned every 1 to $4 \mathrm{~d}$ until wasps emerged. 
Table 1. Classification of parasitised and unparasitised puparia of Musca domestica using NIR spectra and calibrations developed using partial least squares (PLS) regressions.

\begin{tabular}{|c|c|c|c|c|c|c|c|}
\hline \multirow[t]{2}{*}{ Group $^{\mathrm{a}}$} & \multicolumn{2}{|c|}{ No. puparia } & \multirow{2}{*}{$\begin{array}{l}\text { Days before wasp } \\
\text { emergence }\end{array}$} & \multicolumn{4}{|c|}{ Correct classification rate $(\%)^{\mathrm{c}}$} \\
\hline & Un. $^{b}$ & Para. $^{\text {b }}$ & & $\begin{array}{l}\text { No. PLS } \\
\text { factors }\end{array}$ & Un. & Para. & Avg. ${ }^{d}$ \\
\hline \multirow[t]{5}{*}{1} & 71 & 137 & 1 & 8 & 77.5 & 90.5 & 84.0 \\
\hline & & & 3 & 9 & 88.7 & 81.8 & 85.3 \\
\hline & & & 5 & 10 & 80.3 & 78.1 & 79.2 \\
\hline & & & 8 & 14 & 77.5 & 75.9 & 76.7 \\
\hline & & & 10 & 9 & 74.6 & 77.4 & 76.0 \\
\hline \multirow[t]{5}{*}{2} & \multirow[t]{5}{*}{105} & \multirow[t]{5}{*}{102} & 1 & 17 & 82.8 & 88.2 & 85.5 \\
\hline & & & 3 & 18 & 78.1 & 87.3 & 82.7 \\
\hline & & & 5 & 19 & 79.1 & 91.2 & 85.2 \\
\hline & & & 7 & 14 & 78.1 & 91.2 & 84.7 \\
\hline & & & 8 & 13 & 71.4 & 88.2 & 79.8 \\
\hline \multirow[t]{5}{*}{3} & 126 & 20 & 1 & 5 & 100 & 85.0 & 92.5 \\
\hline & & & 4 & 7 & 96.8 & 80.0 & 88.4 \\
\hline & & & 7 & 11 & 97.6 & 80.0 & 88.8 \\
\hline & & & 11 & 11 & 98.4 & 80.0 & 89.2 \\
\hline & & & 14 & 13 & 96.0 & 75.0 & 85.5 \\
\hline 4 & 19 & 78 & 1 & 6 & 63.2 & 92.3 & 77.8 \\
\hline 5 & 33 & 60 & 3 & 3 & 87.9 & 90.0 & 89.0 \\
\hline
\end{tabular}

${ }^{a}$ Groups 13 were exposed to Muscidifurax zaraptor; groups 4 and 5 were exposed to Spalangia cameroni and Muscidifurax raptorellus, respectively

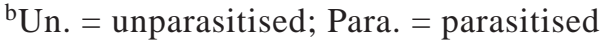

${ }^{c}$ For each group, the parasitisation of each puparium was predicted by using a calibration developed from all remaining puparia from only that group

${ }^{\mathrm{d}}$ Unweighted average

\section{Data analysis}

NIR spectra were analysed using a partial least squares (PLS) regression ${ }^{14}$ and GRAMS software (Galactic, Salem, NH, USA). For developing calibrations, unparasitised and parasitised puparia were arbitrarily assigned a value of 1 and 2, respectively. Identical results are achieved if other numbers are assigned to unparasitised and parasitised puparia during calibrations. Puparia were considered parasitised if predicted values were greater than a rejection threshold, and all others were considered unparasitised. To simplify presentation of results, the rejection threshold was set to 1.5 for all tests. Selecting other rejection thresholds, which is useful if 
the calibration set is unbalanced, can change the correct classification rate for unparasitised and parasitised puparia but does not significantly change the average classification rate. Since the correct classification rates for both unparasitised and parasitised puparia are important, the unweighted average classification rate is reported so that large numbers of parasitised or unparasitised puparia in unbalanced data sets do not skew results.

Cross-validation and prediction sets were used in the analyses. The cross-validation method attempts to emulate the prediction of unknown samples by using the training data set itself. To do this, one sample was removed from the data set, a calibration was developed with the remaining samples, and the removed sample was predicted. This was repeated for all samples and a calibration was selected using the number of factors recommended by the PLS software. The recommended number of PLS factors is based on the reduction in predictive residual sum of squares (PRESS) gained by including additional PLS factors in the calibration model. Cross-validation calibrations and classification results were calculated separately for each group of puparia.

To determine how well one calibration predicted the parasitisation of all puparia, a calibration was developed by randomly selecting $80 \%$ of the group 2 puparia $3 \mathrm{~d}$ before wasp emergence. All puparia in all groups then were predicted with that calibration. Classification errors resulting from this calibration likely would contain a large component due to instrument variability because tests spanned about 10 months, spectra were collected from two different instruments and most tests used different NIR sensor gain settings.

Spectral regions sensitive to differences between parasitised and unparasitised puparia were determined from beta coefficients and difference spectra. For any given wavelength, the absolute value of the beta coefficient indicates how important that wavelength was for classification. Thus, beta coefficient plots can be compared to NIR absorptions of specific functional groups to indicate which molecules contribute to unique NIR absorptions between parasitised and unparasitised puparia. Difference spectra, calculated by subtracting spectra of unparasitised puparia from those of parasitised puparia, also indicate regions of interest.

\section{Results and discussion}

Cross-validation results for the five separate groups (Table 1) showed that the average rates of classification for parasitised and unparasitised puparia ranged from about 76 to $93 \%$. The number of puparia correctly classified generally increased as the days before parasitoid emergence decreased. As a parasitoid feeds on a fly pupa within the puparium, it increases in size, while the fly pupal biomass decreases correspondingly. Therefore, differences between NIR absorption characteristics of parasitised and unparasitised puparia should be greatest just before wasp emergence. However, the success of classifying puparia up to $14 \mathrm{~d}$ before emergence indicates that differences are detectable even when parasitoids are in early stages of their development. Considering shipping and handling constraints for delivering parasitised puparia from commercial insectaries to field locations, a five-day leeway prior to wasp emergence would be ideal.

The optimum number of PLS factors that resulted in the lowest classification errors ranged from 3 to 19. However, selecting 10 PLS factors for all models gave classification results similar to those achieved with the optimum number. Classification rates ranged from about $62 \%$ to $94 \%$ when all puparia were predicted using the calibration developed from the group 2 puparia $3 \mathrm{~d}$ before wasp emergence (Table 2).

Prediction of parasitised and unparasitised puparia of Musca domestica from NIR spectra. All puparia were predicted using a partial least squares regression calibration developed from $80 \%$ of group 2 puparia 3 d before wasp emergence (10 factors).

The difference spectrum (Figure 1) and beta coefficients (Figure 2) indicate where absorbance of NIR radiation by parasitised and unparasitised puparia may be unique. Similar difference spectra and beta coefficients were observed for all tests. Important wavelengths appear to be at $735,810,935,1145$, $1210,1345,1400,1470,1575$ and $1655 \mathrm{~nm}$. Wavelengths common to the difference spectra and beta coefficients occurred at $1145 \mathrm{~nm}$ and from 1320 to $1420 \mathrm{~nm}$. The $1145 \mathrm{~nm}$ region corresponds to the $\mathrm{C}-\mathrm{H}$ 2nd overtones, whereas the $1320-1420 \mathrm{~nm}$ region corresponds to $\mathrm{C}-\mathrm{H}$ combinations and $\mathrm{O}-\mathrm{H} 1$ st overtones. ${ }^{15}$ These absorption differences may be 
Table 2. Prediction results for all groups averaged about $2 \%$ lower than results achieved from calibrations developed for each individual group. These results indicate that a calibration developed by using spectra collected from parasitised puparia of one age can be used to classify puparia of other ages, puparia originating from either laboratory or commercial sources, and puparia containing parasitoids of different species.

\begin{tabular}{|c|c|c|c|c|c|c|}
\hline \multirow[t]{2}{*}{ Group $^{a}$} & \multicolumn{2}{|c|}{ No. puparia } & \multirow{2}{*}{$\begin{array}{l}\text { Days before wasp } \\
\text { emergence }\end{array}$} & \multicolumn{3}{|c|}{ Correct classification rate $(\%)$} \\
\hline & $\mathrm{Un}^{\mathrm{b}}$ & Para. $^{b}$ & & Un. & Para. & Avg. ${ }^{\circ}$ \\
\hline \multirow[t]{5}{*}{1} & \multirow[t]{5}{*}{71} & \multirow[t]{5}{*}{137} & 1 & 60.6 & 93.5 & 77.1 \\
\hline & & & 3 & 60.6 & 98.6 & 79.6 \\
\hline & & & 5 & 69 & 93.5 & 81.3 \\
\hline & & & 8 & 46.5 & 98.6 & 72.6 \\
\hline & & & 10 & 23.9 & 100 & 62.0 \\
\hline \multirow[t]{5}{*}{2} & \multirow[t]{5}{*}{105} & \multirow[t]{5}{*}{102} & 1 & 90.5 & 56.3 & 73.4 \\
\hline & & & 3 & 83.8 & 84.4 & 84.1 \\
\hline & & & 5 & 68.6 & 89.3 & 79.0 \\
\hline & & & 7 & 65.7 & 87.4 & 76.6 \\
\hline & & & 8 & 37.1 & 99.0 & 68.1 \\
\hline \multirow[t]{5}{*}{3} & \multirow[t]{5}{*}{126} & \multirow[t]{5}{*}{20} & 1 & 96.8 & 90.5 & 93.7 \\
\hline & & & 4 & 96.8 & 90.5 & 93.7 \\
\hline & & & 7 & 95.2 & 90.5 & 92.9 \\
\hline & & & 11 & 92.1 & 85.7 & 88.9 \\
\hline & & & 14 & 86.5 & 85.7 & 86.1 \\
\hline 4 & 19 & 78 & 1 & 73.7 & 79.5 & 76.6 \\
\hline 5 & 33 & 60 & 3 & 75.8 & 93.3 & 84.6 \\
\hline
\end{tabular}

${ }^{a}$ Groups 13 were exposed to Muscidifurax zaraptor; groups 4 and 5 were exposed to Spalangia cameroni and Muscidifurax raptorellus, respectively

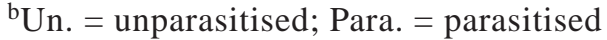

${ }^{\mathrm{c}}$ Unweighted average

due to differences in moisture, chitin or lipid compositions of wasp and fly pupae. Previous research ${ }^{12,13}$ indicates that the $\mathrm{C}-\mathrm{H}$ absorption regions are influenced by chitin or lipids. The overtones of most organic functional groups occur in the $1350-1550 \mathrm{~nm}$ region, so the large absorption difference in this region was expected. The wavelengths reported here agree with those determined by other researchers as resulting from unique absorptions by unparasitised versus parasitised weevils, ${ }^{10}$ various internal wheat pests $^{11,12}$ and adult insects of different species. ${ }^{13}$

The classification rates shown in Table 1 for either the parasitised or unparasitised puparia can be improved by selecting a different rejection thresh- 


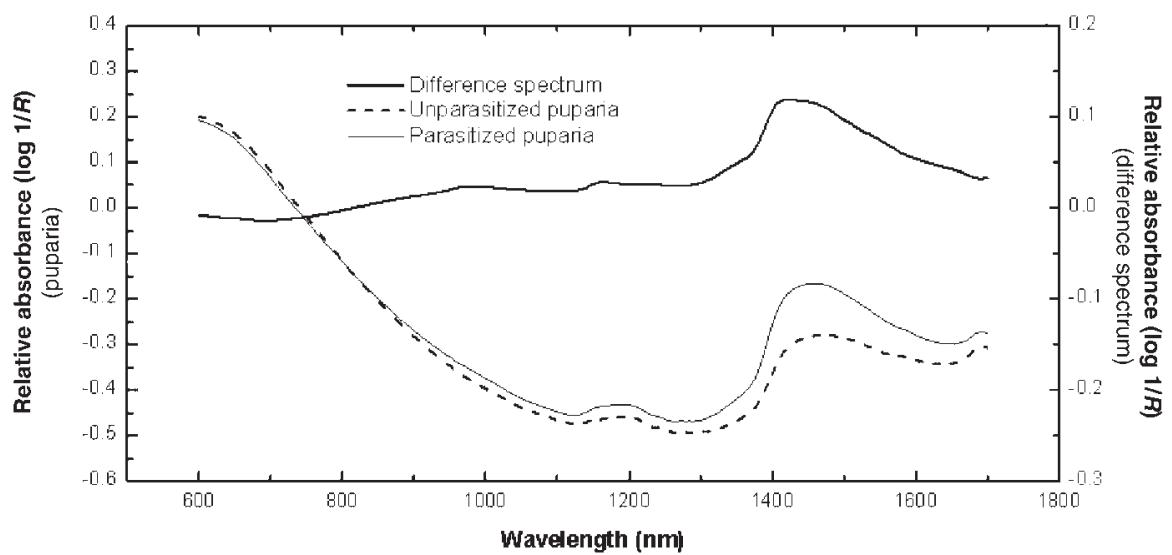

Figure 1. Difference spectrum and typical absorption spectra of parasitised and unparasitised Musca domestica puparia.

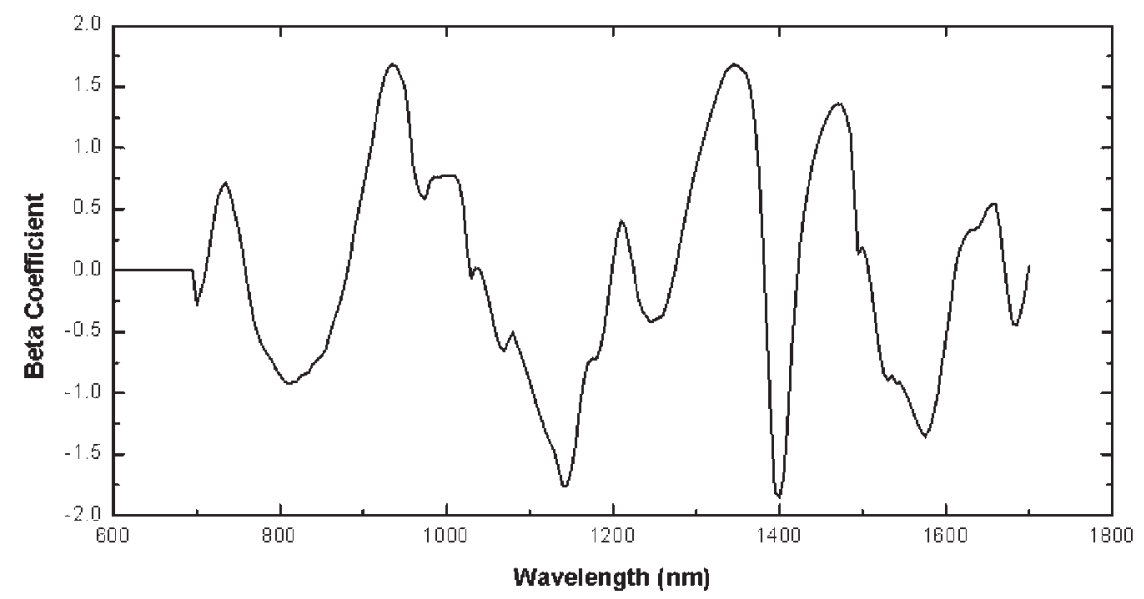

Figure 2. Typical beta coefficients showing important wavelengths used by a partial least squares calibration to classify parasitised and unparasitised Musca domestica puparia.

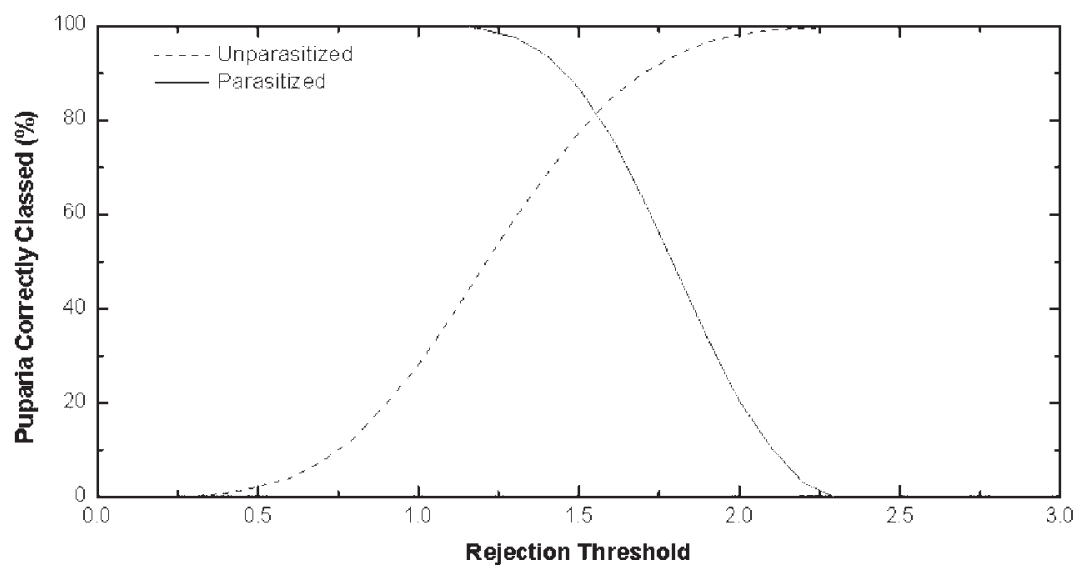

Figure 3. Classification accuracy as a function of rejection threshold when classifying parasitised and unparasitised Musca domestica puparia $5 \mathrm{~d}$ from parasitoid emergence. 
old. Figure 3 shows that the classification rates for unparasitised and parasitised puparia (group 2, $5 \mathrm{~d}$ from parasitoid emergence) were about $79 \%$ and $90 \%$, respectively, when a rejection threshold of 1.5 was selected. To improve parasitoid classifications, the rejection threshold can be reduced to about 1.25 , which results in about $100 \%$ of parasitised puparia being classified correctly. However, lowering the rejection threshold increases the number of unparasitised puparia incorrectly classified as parasitised. Conversely, if the rejection threshold is increased to about 2.0 , then $>95 \%$ of the unparasitised puparia are classified correctly, but about $60 \%$ of parasitised puparia would be misclassified as unparasitised. Therefore, the rejection threshold can be adjusted to correctly classify more parasitised or unparasitised puparia as needed for insectaries to optimise the delivery of viable parasitoids for controlling pest insects in specific situations.

The distinct peaks in the beta coefficient plots indicate that a filter-based NIR sensor could give similar classification results. Such a sensor would be significantly cheaper than the diode-array used in this research, thus lowering costs if a commercial instrument was developed to sort parasitised from unparasitised puparia. Research to determine which specific chemical components cause unique absorptions is needed. In addition, research to select specific wavelengths necessary for correct classification using a filter-based NIR sensor integrated with an automated sorting system also is needed. This technology could be used to evaluate parasitoid levels in the field, could provide commercial insectaries with an automated means of sorting fly puparia during production of beneficial insects and could be applied to many other parasitoid species.

\section{Acknowledgement}

We thank Duane Walker for his instrumentation expertise, Natasha Rowley for assistance in collecting spectra and analysing data, and Kent Hampton for assistance in obtaining puparia.

\section{References}

1. B. Greenburg, Flies and Disease, Vol. 2. Princeton University Press, Princeton (1973).

2. J.A. Meyer, B.A. Mullens, T.L. Cyr and C.J. Stokes, J. Econ. Entomol. 83, 799 (1990).

3. B.D.L. Horton, D.C Sheppard, M.P. Nolan, Jr, R.J. Ottens and J.A. Joyce, J. Agric. Entomol. 2, 196 (1985).

4. C.J. Geden, D.A. Rutz, R.W. Miller and D.C. Steinkraus, Environ. Entomol. 21, 1419(1992).

5. G.L. Greene, J.A. Hogsette and R.S. Patterson, J. Econ. Entomol. 82, 412 (1989).

6. R.A. Weinzierl and C.J. Jones, J. Econ. Entomol. 91, 1114 (1998).

7. J. Zdarek, in Comprehensive Insect Physiology, Biochemistry and Pharmacology, Ed by G.A. Kerkut and L.I. Gilbert. Pergamon Press, New York, Vol. 8, pp. 301-333 (1985).

8. C.G. Jackson, H.T. Chan, Jr, M.H. Taniguchi, D.B. Churchill and D.M. Bilsland, J. Econ. Entomol. 89, 353 (1996).

9. I. Murray and P.C. Williams, in Near-Infrared Technology in the Agricultural and Food Industries, Ed by P.C. Williams and K.H. Norris. American Association of Cereal Chemists, St Paul, MN, pp. 17-34 (1990).

10. J.E. Baker, F.E. Dowell and J.E. Throne, Biol. Control 16, 88 (1999).

11. F.E. Dowell, J.E. Throne and J.E. Baker, J. Econ. Entomol. 91, 899 (1998).

12. C. Ridgway and J. Chambers, J. Sci. Food Agric. 71, 251 (1996).

13. F.E. Dowell, J.E. Throne, D. Wang, and J.E. Baker, J. Econ. Entomol. 92, 165 (1999).

14. H. Martens and T. Næs, Multivariate Calibration. John Wiley \& Sons, Chichester, UK (1989).

15. J.S. Shenk, J.J. Workman, Jr and M.O. Westerhaus, in Handbook of Near-Infrared Analysis, Ed by D.A. Burns and E.W. Ciurczak. Marcel Dekker, New York, NY, pp. 383-431 (1992).

Received: 22 November 1999

Revised: 14 June 2000

Accepted: 11 July 2000

Web Publication: 13 December 2000 